\title{
Insulin Resistance in Type 1 Diabetes Mellitus and Its Association with Patient's Micro- and Macrovascular Complications, Sex Hormones, and Other Clinical Data
}

Diana Šimonienè $\cdot$ Aksana Platūkiene $\cdot$ Edita Prakapienė

Lina Radzevičienè · Džilda Veličkiene

Received: September 2, 2019 / Published online: December 2, 2019

(C) The Author(s) 2019

\section{ABSTRACT}

Introduction: The main objective of this research was to evaluate the association of insulin resistance (IR) with micro- and macrovascular complications, sex hormones, and other clinical data.

Methods: Cross-sectional study of patients older than 18 years old with type 1 diabetes mellitus (T1DM) was performed. Participants filled in questionnaires about T1D, disease duration, smoking, glycemic control, chronic

Enhanced digital features To view enhanced digital features for this article go to https://doi.org/10.6084/ m9.figshare.10248191.

D. Šimonienè $(\varangle) \cdot$ E. Prakapienè .

L. Radzevičienè · D. Veličkiene

Department of Endocrinology, Lithuanian

University of Health Sciences (LUHS), Kaunas,

Lithuania

e-mail: simoniene.diana@gmail.com

L. Radzevičienè · D. Veličkiene

LUHS, Institute of Endocrinology, Kaunas,

Lithuania

A. Platūkiene

Department of Family Medicine, LUHS, Kaunas, Lithuania diabetes complications, and hypertension status. Data about chronic diabetic complications (neuropathy, retinopathy, and nephropathy) were collected from medical records. History of major cardiovascular events such as angina, myocardial infarction, and stroke were collected from medical records also. Laboratory tests including creatinine, cholesterol levels, testosterone (T), sex hormone-binding globulin (SHBG), estradiol levels, and albumin in 24-h urine sample were performed. IR was calculated using the following formula: estimated glucose disposal rate $(\mathrm{eGDR})=24.31-[12.22 \times$ waist to-hip ratio $(\mathrm{WHR})]-[3.29 \times$ hypertension status (defined as $0=$ no, $1=$ yes) $]-[0.57 \times$ glycated hemoglobin (HbA1c)]. The data was considered statistically significant at $p<0.05$.

Results: A total of 200 people (mean age $39.9 \pm 12.1$ years) with T1D were included in the study. Patients with T1D were analyzed according to eGDR levels stratified by tertiles. The cutoff value of eGDR which reflects IR was less than $6.4 \mathrm{mg} \mathrm{kg}^{-1} \mathrm{~min}^{-1}$. When eGDR was less than $6.4 \mathrm{mg} \mathrm{kg}^{-1} \mathrm{~min}^{-1}$, diabetes microvascular complications occurred significantly more often $(p<0.001)$; the cutoff of eGDR for cardiovascular disease (CVD) events was less than $2.34 \mathrm{mg} \mathrm{kg}^{-1} \mathrm{~min}^{-1}$. Lower eGDR, longer diabetes duration, and lower HbA1c significantly increased CVD outcomes risk. eGDR was also significantly lower in smokers $(7.3 \pm$ 2.5 vs. non-smokers $8.2 \pm 2.6, p=0.011)$, the obese (lean $8.25 \pm 2.47$ vs. obese $5.36 \pm 2.74$, 
$p<0.000$ ), older patients (less than 50 years $8.0 \pm 2.5$ vs. more than 50 years $6.2 \pm 2.8$, $p=0.001$ ), men (men $6.4 \pm 2.4$ vs. women $8.7 \pm 2.2, p<0.001)$, patients with long-standing diabetes $(<10$ years $7.3 \pm 2.6$ vs. $>10$ years $8.7 \pm 2.3, p<0.001)$, and chronic diabetes complications (diabetic retinopathy, diabetic nephropathy, diabetic neuropathy, $p<0.001$ ), and patients with CVD (with CVD $5.5 \pm 2.4$ vs. no CVD $8.0 \pm 2.4, p<0.001)$. Patients with T1D and a family history of T2D were not susceptible to weight gain during intensive insulin treatment. Metabolic syndrome (MS) phenotype prevalence, including and dyslipidemia rate, were higher in the obese group than in normal weight, but a clear difference was not seen $(p=0.07)$. Positive linear correlation between men's T and eGDR level was observed $(r=0.33, p=0.04)$, i.e., men with higher testosterone level had better insulin sensitivity. Other parameters (like $\mathrm{T}$ in women, estrogens, SHBG) did not show any significant association with eGDR.

Conclusions: According to stratified eGDR, IR was found for one-third of the current T1D population. Insulin resistant patients more frequently had microvascular complications and CVD events. Lower eGDR, longer diabetes duration, and lower HbA1c significantly increased CVD outcomes risk. IR was related to smoking, obesity, gender, age, and diabetes duration. Moreover, men's testosterone had a positive correlation with IR in T1D. Finally, patients with T1D and a positive family history of T2D were not susceptible to weight gain, while MS metabolic phenotype prevalence tended to be higher in obese than in lean patients with T1D, with a tendency to significant difference.

Keywords: Cardiovascular disease; Estimated glucose disposal rate; Insulin resistance; Insulin sensitivity; Metabolic syndrome; Obesity; Overweight; Type 1 diabetes

\section{Key Summary Points}

\section{Why have we carried out this study?}

Prevalence of overweight and obesity among individuals with type 1 diabetes (T1D) is increasing. Obesity is an independent risk factor for cardiovascular diseases (CVD) which are the dominant cause of mortality in diabetic patients. There is data implying that insulin resistance (IR) develops in patients with T1D as well as in patients with T2D, but little attention is paid to this problem in clinical practice and clinical research; it is thought it might be related to diabetes complications, CVD, testosterone (T), and sex hormone-binding globulin (SHBG) levels. There is inconsistency in data regarding how IR might be diagnosed in T1D

We aimed to determine the estimated glucose disposal rate (eGDR) level (cutoff) that reflects IR and to evaluate the association of IR with micro- and macrovascular complications, sex hormones, and other clinical data

We decided to examine the relation between IR and weight and sex hormones in T1D as the relation between of SHBG and T1D is not clear; little is known about the interaction between T, SHBG levels, and insulin sensitivity in T1D

\section{What was learned from the study?}

Our study is the first one that assessed CVD risk according to eGDR. We found that IR expressed as eGDR cutoff less than $6.4 \mathrm{mg} \mathrm{kg}^{-1} \mathrm{~min}^{-1}$ was significant for all diabetes vascular complication progression and less than $2.3 \mathrm{mg} \mathrm{kg}^{-1} \mathrm{~min}^{-1}$ for CVD. Moreover, eGDR was significantly lower in the obese, smokers, men, subjects aged over 50 years, and in those with long-standing T1D 
Positive linear correlation was observed between men's T and eGDR level, i.e., men with higher $\mathrm{T}$ level had better insulin sensitivity. Other parameters such as $\mathrm{T}$ in women, estrogens, and SHBG did not show any significant association with eGDR. Our results contradict the results of other studies and point to the need for additional research

We found that obese patients with T1D were significantly more insulin resistant and the prevalence of metabolic syndrome tended to be higher in obese than in lean patients with T1D, with a tendency to significant difference. This is in line with previous results of other studies and has reasonably understood pathogenic mechanisms

\section{INTRODUCTION}

Type 1 diabetes (T1D) is autoimmune disease characterized by absolute insulin deficiency. Although impaired insulin action called insulin resistance (IR) is the pathogenic basis of type 2 diabetes (T2D), it can also affect patients with T1D [1].

The etiology of IR in T1D is probably multifactorial, involving both genetic and environmental factors as well as their interplay [2, 3]. Several environmental factors such as acquired lifestyle IR, exogenous insulin therapy induced IR (over-insulinization), and genetic/familial IR are thought to underlie the phenotype of double diabetes. According to Cleland [3], genetic and lifestyle factors that lead to T2D may exist as IR is a syndrome that includes hyperinsulinemia, dyslipidemia (defined as high triglycerides and low HDL levels), hypertension, and obesity [4]. Adiposity has been hypothesized to be the main underlying factor leading to development of IR [2]. However, studies that explored the relation between lifestyle factors and IR in detail are limited.

Nowadays, there is a rising trend of overweight and obesity among individuals with T1D $[5,6]$. Obesity or overweight in T1D results from physical inactivity, sedentary lifestyle, and changes in diet (increased sugar and fast carbohydrate consumption). This is often associated with IR or changes of lifestyle that may lead to IR, increased insulin dose requirements, and poor glycemic control. Moreover, increased insulin dose increases insulin-induced weight gain that triggers IR-a vicious circle.

Family history of T2D is another clinical factor that may also increase the risk for IR [7]. But there is an important unanswered question according to Cleland [3]: Are these T1D patients with a family history of T2D more susceptible to weight gain during intensive insulin treatment?

Better knowledge of factors controlling IR in T1D is important not least because of strong evidence for the relationship between IR and cardiovascular disease (CVD) [4, 8, 9]. Several studies [10-13] have also shown a clear association between IR and an increased incidence of chronic complications in people with T1DM.

Moreover, several factors have been suggested to influence IR progression in T1D $[1,14]$. It is known, that IR is also associated with sex hormones [15]. It was found that sex hormone-binding globulin (SHBG) has an additional biologic effect. Recent evidence demonstrates an association between SHBG and insulin resistance [16]. Obesity and hyperinsulinemia have been associated with decreased levels of SHBG $[17,18]$. While the data is controversial, a study from Denmark has shown increased SHBG level in men with T1D [19]. There is a lack of data demonstrating clear association between SHBG and IR in the T1D population.

In men, low testosterone level is associated with obesity, hyperglycemia, and hyperinsulinemia [20], whereas hyperandrogenicity is associated with an increased risk for T2D and CVD events in women [21]. Moreover, a high predominance of low testosterone (T) in men with T2D has been reported in several studies $[22,23]$, but little is known about the interaction between $\mathrm{T}$ levels and insulin sensitivity in T1D [16]. Moreover, data about steroid levels presented in the literature are controversial. In most studies, $\mathrm{T}$ levels did not differ between T1D [24] and controls groups, while Christensen et al. found higher $\mathrm{T}$ level in patients 
with T1D [19]. Nevertheless, these studies did not evaluate the patient's insulin sensitivity according to sex hormones.

The gold standard method of evaluating insulin sensitivity is the hyperinsulinemic-euglycemic clamp. As this is a time-consuming and invasive experimental technique [3], it is impractical for large and populationbased studies. The estimated glucose disposal rate (eGDR) is a "best-fit" model derived from euglycemic-hyperinsulinemic clamp studies and has been validated for the estimation of IR in individuals with T1D [10].

Lower eGDR was related to higher IR in many studies [10-13]. Epstein et al.'s study [10] explored inter-ethnic differences in eGDR, while other authors searched for a relation between eGDR and a certain chronic diabetes complication (retinopathy, nephropathy, or cardiovascular), or among eGDR and a diabetes complication and metabolic syndrome (MS) for long-standing disease. Nevertheless, these trials did not evaluate risk factors for different patients' insulin sensitivity, according to anthropometric measures, between those who are lean versus those who have the MS phenotype. Also there are several comparisons between different diabetes complications according to eGDR, but CVD events risk evaluation was not included; furthermore what eGDR value is significant in evaluating the risk of progression of vascular complications is still under discussion. This is the first evaluation of IR in a group of Lithuanian patients with T1D using mathematical formulae and MS markers. The main objective of this research was to evaluate the association of IR with micro- and macrovascular complications, sex hormones, and other clinical data.

\section{METHODS}

\section{Study Population}

It was a prospective, cross-sectional study that included 200 unselected patients with T1D over the age of 18 years with diabetes duration at least 1 year; patients were men and women with regular menstrual cycle (without signs of pregnancy or menopause stage). Data were collected from February 2015 until April 2016 at the study center of our university hospital. Informed consent was obtained from all individual participants involved in the study.

\section{Data Collection}

Participants filled in questionnaires about demographic data (such as age, gender, diabetes duration in years), current insulin dose, smoking, glycemic control, chronic diabetes complications, and hypertension status. Clinical history of major cardiovascular events (heart attack, ischemic heart disease, stroke, and peripheral vascular disease) and diabetes complications (micro- or macroalbuminuria, retinopathy, peripheral neuropathy) were collected from medical records.

MS, as an indicator of IR, was defined by the following criteria according to the National Cholesterol Education Program (NCEP) Adult Treatment Panel III (ATP III): abdominal obesity (waist circumference $>102 \mathrm{~cm}$ in men or $>88 \mathrm{~cm}$ in women), hypertension (blood pressure $\geq 130 / 85 \mathrm{mmHg}$ ), and hyperlipidemia (plasma triglycerides $\geq 1.7 \mathrm{mmol} / \mathrm{l}, \quad \mathrm{HDL}$ cholesterol $<1.03 \mathrm{mmol} / \mathrm{l}$ in men or $<1.29 \mathrm{mmol} / \mathrm{l}$ in women) [25]. Dyslipidemia was diagnosed according to aforementioned criteria. Weight, height, waist (WC) and hip (HC) circumferences were measured on participants wearing only light underwear. Body height (in centimeters) was measured to the nearest $0.5 \mathrm{~cm}$ without shoes using a stadiometer and weight (in kilograms) was measured to the nearest $0.1 \mathrm{~kg}$. WC (in centimeters) was measured at the narrowest point below the ribs using a measuring tape. HC (in centimeters) was measured at the broadest circumference below the waist. BMI was calculated as weight divided by height squared (kilograms per square meter) and waist-to-hip ratio was calculated as WC divided by HC. BMI was categorized into groups according to the conventional World Health Organization (WHO) classification [26]: normal weight $\left(18.5-24.9 \mathrm{~kg} / \mathrm{m}^{2}\right)$, overweight $\left(25-29.9 \mathrm{~kg} / \mathrm{m}^{2}\right)$, and obese $\left(\geq 30 \mathrm{~kg} / \mathrm{m}^{2}\right)$. 
Insulin sensitivity was measured with eGDR calculated as $24.31-(12.22 \times$ WHR $)-$ $(3.29 \times \mathrm{HT})-(0.57 \times \mathrm{HbA} 1 \mathrm{c})$, where WHR is waist-to-hip ratio; HT is hypertension; HbA1c is the value of glycated hemoglobin in percent. The calculated eGDR units are milligrams per kilogram per minute $[27,28]$.

The clinical and laboratory data included the diabetic care profile (HbA1C) and 24-h urinary protein excretion (0-300 $\mathrm{mg}$ /day), hemo-analyses and chemistry (creatinine, 59-104), lipid profile (total cholesterol, $\quad 0-5.2 \mathrm{mmol} / \mathrm{l}$; triglycerides (TG), $\quad 0-1.7 \mathrm{mmol} / \mathrm{l}$; high-density lipoproteins (HDL), > $1.55 \mathrm{mmol} / \mathrm{l}$; and low-density lipoprotein (LDL), $0-2.6 \mathrm{mmol} / \mathrm{l})$. Venous blood was collected in the morning after an overnight fast using an automatic analyzer (Beckman Coulter, USA, AU 680 in the Clinical Laboratory of the Hospital of Lithuanian University of Health Sciences Kaunas Clinics). The classification and pathological scoring of diabetic nephropathy were carried out according to the criteria of Tervaert et al. [29].

\section{Compliance with Ethics Guidelines}

All procedures followed were in accordance with the ethical standards of the responsible committee on human experimentation (Kaunas Regional Biomedical Research Ethics Committee, Nr. LitDiane-01 version 2, 2013-11-07) and with the Helsinki Declaration of 1975 , as revised in 2013. Informed consent was obtained from all patients for being included in the study.

\section{Hormone Assays}

For most participants of the study, venous blood was obtained in the morning and serum was separated immediately.

For the cohort, serum levels of total testosterone were determined by radioimmunoassay (Biosource, Belgium, normal range $<0.17-2.65$ $\mathrm{nmol} / \mathrm{l})$, estradiol was determined by radioimmunoassay (Immunotech, Czech Republic, normal range $128-541 \mathrm{pmol} / \mathrm{l})$, and SHBG was determined by radioimmunoassay (Immunotech, Czech Republic, normal range 20-85
Table 1 Clinical characteristics of participants

\begin{tabular}{|c|c|}
\hline Characteristic & Incident case \\
\hline Age (years) & $39.9 \pm 12.1$ \\
\hline Gender (male/female), \% & $42.0 / 58.0$ \\
\hline Disease duration (years) & $16.4 \pm 10.8$ \\
\hline WHR & $0.88 \pm 0.11$ \\
\hline $\operatorname{BMI}\left(\mathrm{kg} / \mathrm{m}^{2}\right)$ & $24 \pm 4.1$ \\
\hline $\mathrm{BMI}>25 \mathrm{~kg} / \mathrm{m}^{2}, n(\%)$ & $73(36.5)$ \\
\hline HbAlc (\%) & $8.9 \pm 2.0$ \\
\hline $\mathrm{HDL}(\mathrm{mmol} / \mathrm{l})$ & $1.56 \pm 0.66$ \\
\hline Triglyceride (mmol/l) & $1.34 \pm 0.04$ \\
\hline Hypertension, $n(\%)$ & $73(36.5)$ \\
\hline Insulin dose/weight (U/kg) & $0.77 \pm 0.24$ \\
\hline Smoking, $n(\%)$ & $88(44.0)$ \\
\hline Positive family history of T2D, $n(\%)$ & $66(33.0)$ \\
\hline $\begin{array}{l}\text { Total testosterone level in men ( } \mathrm{nmol} / \\
\text { l) }\end{array}$ & $19.56 \pm 8.09$ \\
\hline $\begin{array}{l}\text { Total testosterone level in women } \\
(\mathrm{nmol} / \mathrm{l})\end{array}$ & $2.47 \pm 1.48$ \\
\hline Estradiol level in men $(\mathrm{pmol} / \mathrm{l})$ & $270.26 \pm 119.08$ \\
\hline Estradiol level in women ${ }^{\mathrm{a}}(\mathrm{pmol} / \mathrm{l})$ & $440 ; 73.4 / 3431.0$ \\
\hline SHBG level in men $(\mathrm{nmol} / \mathrm{l})$ & $37.4 \pm 18.4$ \\
\hline SHBG level in women $(\mathrm{nmol} / \mathrm{l})$ & $74.0 \pm 39.3$ \\
\hline FAI in women ${ }^{a}$ & $3.06 ; 0.24 / 28.05$ \\
\hline
\end{tabular}

Data are presented as mean \pm SD unless otherwise specified

$W H R$ waist-to-hip ratio, $B M I$ body mass index, $H b A l c$ glycated hemoglobin, $H D L$ high-density lipoprotein, $S H B G$ sex hormone-binding globulin, FAI free androgen index

a Data are presented as median; minimum/maximum

$\mathrm{nmol} / \mathrm{l})$. The intra- and inter-assay coefficients of variation (CVs) for measurement of total testosterone were respectively less than $8 \%$ and less than 5\%, CVs for estradiol were $7.5 \%$ and $13 \%$, and CVs for SHBG were less than $6.7 \%$ and less than $8.2 \%$.

Estradiol was measured without regard to the particular phase of menstrual cycle. 
Table 2 Clinical variables in different weight groups assessment according to weight

\begin{tabular}{lllll}
\hline Clinical variable & $\begin{array}{l}\text { Normal weight } \\
\boldsymbol{n}=\mathbf{1 2 7}\end{array}$ & $\begin{array}{l}\text { Overweight } \\
\boldsymbol{n}=\mathbf{5 8}\end{array}$ & $\begin{array}{l}\text { Obese } \\
\boldsymbol{n}=\mathbf{1 5}\end{array}$ & $\boldsymbol{p}$ value \\
\hline Gender, female/male, $n(\%)$ & $75 / 52(59 / 41)$ & $33 / 25(56.9 / 43.1)$ & $6 / 9(40 / 60)$ & 0.34 \\
Age, years, mean \pm SD & $33.4 \pm 10.9$ & $36.2 \pm 12.5$ & $42.9 \pm 16.3$ & 0.007 \\
HbAlc (\%), mean \pm SD & $9.0 \pm 2.1$ & $8.7 \pm 2.1$ & $9.1 \pm 1.7$ & 0.13 \\
eGDR (mg kg ${ }^{-1}$ min $^{-1}$ ), mean \pm SD & $8.25 \pm 2.47$ & $7.45 \pm 2.46$ & $5.36 \pm 2.74$ & 0.000 \\
Insulin dose (IU/kg), mean \pm SD & $0.73 \pm 0.24$ & $0.73 \pm 0.21$ & $0.74 \pm 0.25$ & 0.46 \\
Dyslipidemia, $n(\%)$ & $57(44.9)$ & $29(50.0)$ & $11(73.3)$ & 0.06 \\
MS signs, $n$ (\%) & $40(31.5)$ & $18(31.0)$ & $9(60.0)$ & 0.07 \\
Positive family history, $n$ (\%) & $44(34.6)$ & $18(31.0)$ & $4(26.7)$ & 0.77 \\
Hypoglycemia $(\geq 3$ per week), $n(\%)$ & $12(9.4)$ & $6(10.3)$ & $1(6.6)$ & 0.33 \\
\hline
\end{tabular}

HbAlc glycated hemoglobin, $e G D R$ estimated glucose disposal rate, $M S$ metabolic syndrome, $I U$ international units

\section{Statistical Analysis}

The normality of distribution was tested using the Kolmogorov-Smirnov test. Student's $(t)$ criterion was used for comparison of means for normal distributions, and the Mann-Whitney $(U)$ test was used in skewed distributions. Differences between two means of independent samples were compared using Student's $t$ test. Categorical variables (presented as median values) were compared with the $n$ (proc), $\chi^{2}$ test, or Fisher's exact test. To test the correlations among quantitative variables, Pearson's correlation coefficient $(r)$ was used. eGDR levels were stratified by tertiles. In order to find the difference between more than two groups, parametric and nonparametric dispersive analyses with ANOVA and Kruskal-Wallis test were performed. A multivariate logistic regression method was used to determine the most important relationship factors. Odds ratios (OR) and 95\% confidence intervals (CI) for various parameters were calculated. The optimal cutoff value for CVD events was estimated by the areas under the receiver operating characteristic (ROC) curve analysis and chosen where the "Sensitivity + Specificity" was maximal.

The collected data were analyzed using the Statistic Package for Social Sciences (SPSS) version 22 software. The data was considered statistically significant at $p<0.05$.

\section{RESULTS}

A total of 200 patients with T1D were included in the study. Clinical characteristics of patients with T1D included age, gender, disease duration, BMI, waist-to-hip ratio (WHR), lipids profile, sex hormones, and insulin dose as listed in Table 1.

One-third of the sample had dyslipidemia $(67,33.50 \%)$ and hypertension $(73,36.5 \%)$, whereas mean BMI and WHR were normal. The approximate daily insulin requirement for participants was 0.77 units/kg body weight. Median free androgen index (FAI) in women group was a little bit higher than normal (FAI 3.06).

Age, gender, IR, metabolic factors and family history were evaluated according to BMI. Obese patients had significantly lower eGDR value (higher IR, $p<0.000$ ). Older patients with T1D were significantly more obese $(p=0.007)$ (Table 2). There was no significant difference between BMI groups and diabetes control. HbA1c was about 9\% in all groups. Insulin requirement in all weight groups was equal. One-third of patients with T1D $(66,33.0 \%)$ had a positive family history of T2D (Table 1 ), but these patients were not more susceptible to 
Table 3 Clinical and laboratory characteristics of patients with T1D and association with eGDR

\begin{tabular}{llll}
\hline Variables & Percentage $(n)$ & eGDR & $p$ value
\end{tabular}

Smoking

$\begin{array}{llll}\text { Yes } & 44.0(88) & 7.3 \pm 2.5 & 0.011 \\ \text { No } & 56.0(112) & 8.2 \pm 2.6 & \end{array}$

Gender

$\begin{array}{llll}\text { Male } & 42.0(42) & 6.4 \pm 2.4 & <0.001 \\ \text { Female } & 58.0(58) & 8.7 \pm 2.2 & \end{array}$

HbAlc

$\begin{array}{llll}<7.0 & 15.5(31) & 9.2 \pm 2.2 & <0.001 \\ >7.0 & 84.5(169) & 7.5 \pm 2.5 & \end{array}$

CVD

$\begin{array}{llll}\text { Yes } & 11.5(23) & 5.5 \pm 2.4 \quad<0.001 \\ \text { No } & 88.5(117) & 8.0 \pm 2.4 & \end{array}$

Hypertension

$\begin{array}{llll}\text { Yes } & 36.5(73) & 5.0 \pm 1.4 \quad<0.001 \\ \text { No } & 63.5(127) & 9.3 \pm 1.6 & \end{array}$

Diabetic retinopathy

$\begin{array}{llll}\text { Yes } & 58.5(117) & 7.1 \pm 2.5 & <0.001 \\ \text { No } & 41.5(83) & 8.7 \pm 2.3 & \end{array}$

Diabetic neuropathy

$\begin{array}{llll}\text { Yes } & 67.5(135) & 7.0 \pm 2.5<0.001 \\ \text { No } & 32.5(65) & 9.2 \pm 2.0 & \end{array}$

Microalbuminuria

$\begin{array}{llll}\text { Yes } & 34.0(68) & 6.6 \pm 2.3<0.001 \\ \text { No } & 66.0(132) & 8.3 \pm 2.5 & \end{array}$

Diabetic nephropathy

$\begin{array}{llll}\text { Yes } & 35.5(71) & 6.4 \pm 2.3 \quad<0.001 \\ \text { No } & 64.5(129) & 8.5 \pm 2.4 & \end{array}$

Disease duration

\begin{tabular}{llll}
$<10$ years & $65.5(139)$ & $7.3 \pm 2.6$ & $<0.001$ \\
$>10$ years & $34.5(61)$ & $8.7 \pm 2.3$ & \\
\hline
\end{tabular}

Table 3 continued

\begin{tabular}{llll}
\hline Variables & Percentage $(\boldsymbol{n})$ & eGDR & $\boldsymbol{p}$ value \\
\hline Age & & & \\
$<50$ years & $87.5(175)$ & $8.0 \pm 2.5$ & 0.001 \\
$>50$ years & $12.5(25)$ & $6.2 \pm 2.8$ & \\
\hline
\end{tabular}

HbAlc glycated hemoglobin, CVD cardiovascular disease

weight gain during intensive insulin treatment $(p=0.64)$. Obese patients were more likely to have dyslipidemia and/or other signs of MS, but there was no clear significant difference compared with normal weight subjects (Table 2).

Lower eGDR, i.e. higher IR, was observed in smokers, patients older than 50 years old, male gender, and in those with diagnosed microvascular complications, arterial hypertension, and history of CVD, and decompensated diabetes. Moreover, patients with lower insulin resistance were among those that had worse diabetes control according to HbA1c and longer diabetes duration (more than 10 years) $(p<0.001)$ (Table 3).

To assess the relation of micro- and macrovascular complications with IR, and evaluate a cutoff value of eGDR, study participants were analyzed according to eGDR levels stratified by tertiles: low-1st $\left[<6.4 \mathrm{mg} \mathrm{kg}^{-1}\right.$ $\min ^{-1}$ ], middle-2nd [6.4-9.5 $\mathrm{mg} \mathrm{kg}^{-1} \mathrm{~min}^{-1}$ ], and high-3rd [>9.5 $\left.\mathrm{mg} \mathrm{kg}^{-1} \mathrm{~min}^{-1}\right]$. Participants in the 1st tertile had significantly lower measured insulin sensitivity than participants in the 2nd and 3rd tertiles after adjusting for micro- and macrovascular complications (Table 4). eGDR value less than $6.4 \mathrm{mg} \mathrm{kg}^{-1}$. $\mathrm{min}^{-1}$, that referred to high IR, was found for 67 patients (33.5\%).

The variables that were significantly different between the 1st tertile and 2nd tertile of the eGDR formula data were age, duration of diabetes, BMI, total dose insulin IU/lean mass (kg), HDL, and triglycerides. Pearson's correlation was used to establish correlations among insulin dose per kilogram body weight and eGDR. It was found that higher insulin dose per kilo was inversely associated with eGDR $(r=-0.193$, $p=0.006$ ), while differences among tertiles were not seen. 
Table 4 eGDR, stratified by tertiles, and relation with age, diabetes duration, control, and complications

\begin{tabular}{|c|c|c|c|c|}
\hline \multirow[t]{2}{*}{ Data } & \multicolumn{3}{|c|}{ Glucose disposal rate $\left(\mathrm{mg} \mathrm{kg}^{-1} \min ^{-1}\right)$} & \multirow[t]{2}{*}{$p$ value } \\
\hline & $\begin{array}{l}\text { 1st tertile }<6.4(n=67) \\
(33.5 \%)\end{array}$ & $\begin{array}{l}\text { 2nd tertile } \\
6.4-9.5(n=57) \\
(28.5 \%)\end{array}$ & $\begin{array}{l}\text { 3rd tertile } \\
>9.5(n=76) \\
(38 \%)\end{array}$ & \\
\hline Age (years) & $40.9 \pm 13.1$ & $31.7 \pm 10.1$ & $32.1 \pm 10.7$ & $<0.001^{1,2}$ \\
\hline Disease duration (years) & $21.8 \pm 11.9$ & $14.8 \pm 8.1$ & $12.8 \pm 9.7$ & $<0.001^{1,2}$ \\
\hline $\operatorname{BMI}\left(\mathrm{km} / \mathrm{m}^{2}\right)$ & $26.3 \pm 4.8$ & $23.9 \pm 3.5$ & $23.3 \pm 3.3$ & $\leq 0.004^{1,2}$ \\
\hline Insulin dose (IU/day) & $62.2 \pm 21.2$ & $51.7 \pm 16.3$ & $45.8 \pm 17.8$ & $\leq 0.006^{1,2}$ \\
\hline Insulin dose per kilogram & $0.78 \pm 0.22$ & $0.73 \pm 0.18$ & $0.68 \pm 0.25$ & $0.20^{1,2}$ \\
\hline HbAlc (\%) & $9.7 \pm 2.4$ & $9.5 \pm 1.9$ & $7.8 \pm 1.2$ & $<0.001^{2,3}$ \\
\hline Total cholesterol $(\mathrm{mmol} / \mathrm{l})$ & $5.5 \pm 1.5$ & $5.3 \pm 1.3$ & $5.2 \pm 1.3$ & 0.384 \\
\hline $\mathrm{LDL}(\mathrm{mmol} / \mathrm{l})$ & $3.3 \pm 1.1$ & $3.1 \pm 0.9$ & $2.8 \pm 1.1$ & 0.059 \\
\hline $\mathrm{HDL}(\mathrm{mmol} / \mathrm{l})$ & $1.4 \pm 0.5$ & $1.6 \pm 0.6$ & $1.8 \pm 0.8$ & $0.002^{1,2}$ \\
\hline $\mathrm{TG}(\mathrm{mmol} / \mathrm{l})$ & $1.9 \pm 1.3$ & $1.2 \pm 0.5$ & $1 \pm 0.9$ & $<0.001^{1,2}$ \\
\hline Hypertension & $61(83.6)$ & $12(16.4)$ & 0 & $<0.001$ \\
\hline Smoking & $35(39.8)$ & $27(30.7)$ & $26(29.5)$ & 0.079 \\
\hline Diabetic retinopathy & $52(44.4)$ & $34(29.1)$ & $31(26.5)$ & $<0.001$ \\
\hline Microalbuminuria & $38(54.3)$ & $20(28.6)$ & $12(17.1)$ & $<0.001$ \\
\hline Diabetic nephropathy & $39(54.9)$ & $22(31)$ & $10(14.1)$ & $<0.001$ \\
\hline Diabetic neuropathy & $60(44.4)$ & $42(31.1)$ & $33(24.5)$ & $<0.001$ \\
\hline Cardiovascular disease & $19(82.6)$ & 0 & $4(17.4)$ & $<0.001$ \\
\hline Heart attack & $3(100)$ & 0 & 0 & 0.049 \\
\hline Ischemic heart disease & $12(92.3)$ & 0 & $1(7.7)$ & $<0.001$ \\
\hline Peripheral vascular disease & $14(82.4)$ & 0 & $3(17.6)$ & $<0.001$ \\
\hline Stroke & $3(100)$ & 0 & 0 & 0.049 \\
\hline
\end{tabular}

Data presented as mean $\pm \mathrm{SD}$ or $n(\%)$ and differences counted between the relevant tertiles. Superscript numbers adjacent to $p$ values define the tertiles being compared

$B M I$ body mass index, $H b A 1 c$ glycated hemoglobin, $L D L$ low-density lipoprotein, $H D L$ high-density lipoprotein, $T G$ triglycerides, $I U$ international units

Using ROC curve analysis, we assessed highrisk and low-risk patients for CVD events on the basis of the risk assessment model. On the basis of the area under the ROC curve $(0.78, p<0.00)$, with $95.5 \%$ sensitivity and $99.4 \%$ specificity, the highest rate risk of CVD events occurred when eGDR was less than $2.34 \mathrm{mg} \mathrm{kg}^{-1} \mathrm{~min}^{-1}$ (Fig. 1). To further explore risk factors for CVD events in
T1D, a binary logistic regression model was adopted (Table 5). IR assessed by eGDR was more important for the development of CVD events in patients with T1D than generally accepted CVD risk factors, such as elevated BMI, dyslipidemia, or hypertension (Table 5). Lower eGDR (higher IR), longer diabetes duration, and lower HbA1c increase CVD events risk. 


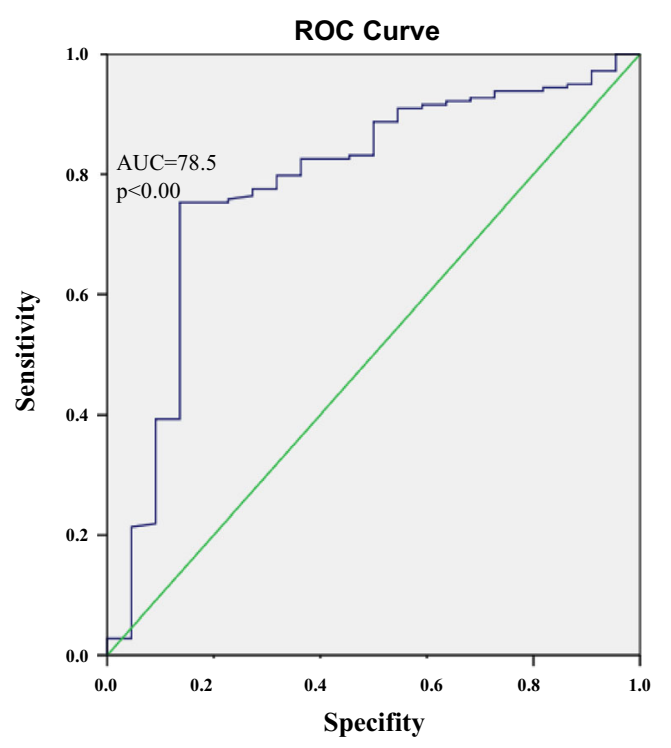

Fig. 1 ROC curve for the highest CVD event risk

The relationship between sex hormones and IR in the population with T1D was also evaluated. Positive linear correlation between men's $\mathrm{T}$ and eGDR level was observed $(r=0.33$, $p=0.04)$, which means that more insulin resistant men (estimated by eGDR) had lower $\mathrm{T}$ level (Fig. 2), but there was no significant association between eGDR level and estrogen, SHBG in both gender, or $\mathrm{T}$ in women $(p>0.05)$.

\section{DISCUSSION}

eGDR is a validated clinical tool for estimating insulin sensitivity in T1D. Quantification of IR and its severity is a challenging task for the clinician, especially when a clear eGDR value is still under discussion. There are several studies that assessed eGDR cutoffs. For example, Tam et al. in their study, which comprised 51 subjects with diabetes and 116 subjects without diabetes, found that $75 \%$ of individuals with an eGDR less than $5.6 \mathrm{mg} \mathrm{kg}^{-1} \mathrm{~min}^{-1}$ were truly insulin resistant [30]. Vladu et al. in a study with 200 patients with T1DM used eGDR of $7.5 \mathrm{mg} \mathrm{kg}^{-1} \mathrm{~min}^{-1}$ as a maximum cutoff for IR, but there was no detailed explanation for this level [31]. Moreover, in a cross-sectional study with 91 patients, Chillarón et al. [11] concluded that diabetes complications occurred in patients in their lowest eGDR tertile $\left(<8.16 \mathrm{mg} \mathrm{kg}^{-1}\right.$ $\left.\min ^{-1}\right)$ : with diabetic retinopathy $(5.97 \pm 1.2)$, diabetic neuropathy $(5.06 \pm 0.4)$, or diabetic nephropathy $(5.79 \pm 1.5)$. Pop and colleagues in cross-sectional study also evaluated IR by eGDR in 272 patients with T1DM. According to Pop et al., eGDR was a good discriminator for each diabetic complication (6.1 vs. $6.9 \mathrm{mg} \mathrm{kg}^{-1} \mathrm{~min}^{-1}$ for retinopathy; $6.3 \mathrm{vs}$. 7.3 for nephropathy; 6.5 vs. 7.6 for neuropathy; and 5.2 vs. 7.5 for cardiovascular complications), with an area under the curve between 0.609 and 0.759 [32]. Division into tertiles for eGDR evaluation was also used by Epstein et al. They conducted a cross-sectional study that included 207 participants with T1D [10] and found most resistant patients at eGDR less than $5.39 \mathrm{mg} \mathrm{kg}^{-1} \mathrm{~min}^{-1}$ according to eGDR tertile. In addition, in the Pittsburgh Epidemiology of Diabetes Complications (EDC) study [33] where eGDR was found from division into quintiles, it was reported that eGDR in the lowest quintile $\left(<6.22 \mathrm{mg} \mathrm{kg}^{-1} \mathrm{~min}^{-1}\right)$ was an independent predictor of diabetes complication progression in patients with T1D. In the current study, a similar cutoff value of less than $6.4 \mathrm{mg} \mathrm{kg}^{-1}$ $\min ^{-1}$ analyzing eGDR level by tertiles was found. Participants in the lowest tertile had significantly lower measured insulin sensitivity. Different values of eGDR as cutoff in various studies may be explained by the use of different statistical methods (stratified into tertiles, quintiles, or estimated by ROC curve) and the differences of studied ethnic groups. According to various data results, eGDR cutoff for IR varied from 5 to $9 \mathrm{mg} \mathrm{kg}^{-1} \mathrm{~min}^{-1}$.

Many studies, including the current one, demonstrated a clear association between IR and incidence of diabetes complications in people with T1DM [10, 11, 32, 34, 35]. The Diabetes Control and Complications Trial (DCCT) was a basic study that revealed the importance of tight glucose control by improving the onset and progression of all diabetic microvascular complications [36]. DCCT demonstrated that intensive diabetes treatment for reaching tight glucose control was associated with weight gain, elevated blood pressure, 
Table 5 Binary logistic regression analysis of various variables influencing CVD events in patients with T1D

\begin{tabular}{llr}
\hline Variable & \multicolumn{2}{l}{ Binary logistic regression } \\
\cline { 2 - 3 } & OR (95\% CI) & \multicolumn{1}{c}{$\boldsymbol{p}$ value } \\
\hline Diabetes duration & $1.127(1.062-1.196)$ & $<0.000$ \\
eGDR & $0.639(0.491-0.830)$ & 0.001 \\
HbAlc & $0.639(0.425-0.962)$ & 0.032 \\
BMI & $1.069(0.907-1.261)$ & 0.426 \\
TG & $1.243(0.779-1.982)$ & 0.361 \\
HDL & $1.667(0.658-4.224)$ & 0.282 \\
Hypertension & $0.610(0.030-1.423)$ & 0.748 \\
\hline
\end{tabular}

$e G D R$ estimated glucose disposal rate, $H b A l c$ glycated hemoglobin, $B M I$ body mass index, $T G$ triglycerides, $H D L$ high-density lipoprotein

and dyslipidemia [37]. Still, in later results from DCCT, intensive glycemic control was associated with better CVD outcomes [38]. Results from the Pittsburgh EDC study showed that IR is a major determinant of CVD associated with T1DM. Current data confirmed that, although conventional risk factors (e.g., hypertension, overweight, dyslipidemia) do generally predict the adverse CVD outcomes, eGDR or IR was the

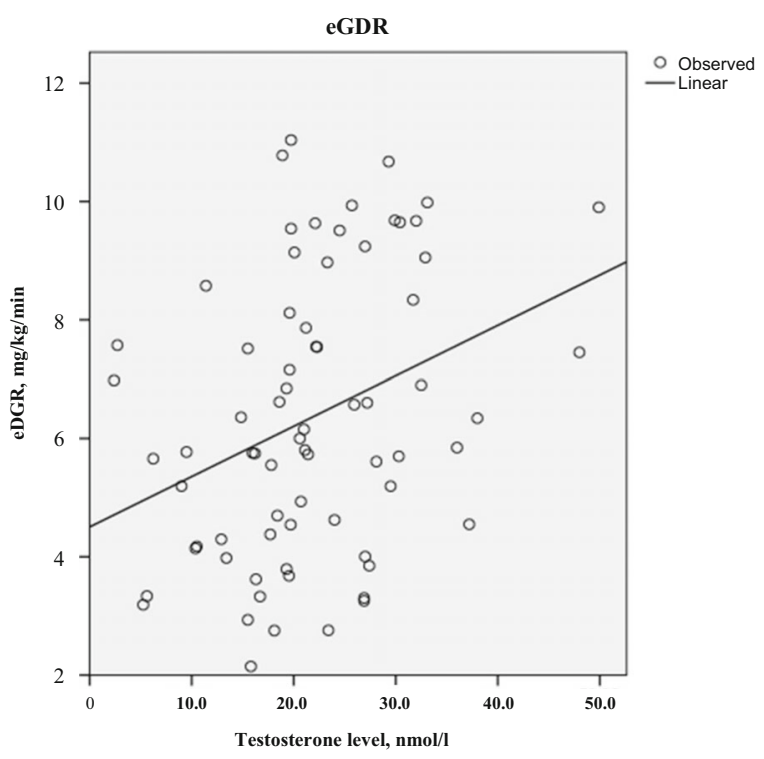

Fig. 2 Scatter plot of the correlation values between eGDR and T level in men with T1D strongest independent factor for CVD. eGDR less than $2.34 \mathrm{mg} \mathrm{kg}^{-1} \mathrm{~min}^{-1}$ significantly increased CVD events risk. This is the first study that assessed CVD risk according to eGDR. Moreover, negative CVD outcomes were also related to longer diabetes duration and lower HbA1c. Bicu et al. [13] also found that eGDR was strongly negatively correlated with CVD events in patients with T1D and diabetes duration longer than 10 years. Interesting, that lower HbA1c had a negative effect on CVD outcomes. It is known that hypoglycemia, which arises from tight glucose control and an intensive insulin regime, itself may increase the risk of CVD [39]. This shows that the personalized target HbA1c is very important, especially if the patient has a long duration of diabetes, and chronic diabetes complications are advanced.

Association between eGDR and other variables was also evaluated. eGDR was significantly lower in smokers, male patients aged 50 years or more, and in long-standing T1D. Older age and long evolution of diabetes are factors known to be associated with IR as shown in numerous studies [31, 40, 41]. A possible explanation for these associations, according to Teixeira et al., is hypertension, a component of the eGDR formula that is more prevalent in patients with T1D after several years of the disease. Moreover, naturally age-related IR also has an influence on lower eGDR. Gender difference in IR is also a known factor. It is believed that greater amounts of visceral and hepatic adipose tissue, simultaneously with the lack of a possible protective effect of estrogen, may be related to higher IR in men compared with women [42]. The relationship between smoking and unfavorable metabolic profile was also demonstrated in many previous studies showing that smokers with T1DM were more IR [43]. However, mechanisms responsible for smoking-induced insulin resistance are unclear. Some data suggest that basal inhibition of insulin signaling may be an important mechanism responsible for smoking-induced IR [44].

Further variables that are associated with IR were examined, including sex hormones. Data on the association between $\mathrm{T}$ levels and IR are inconsistent. In most studies, T levels did not differ between diabetic men and control 
subjects, but in observational studies diabetic men have demonstrated a higher occurrence of hypogonadism when compared with non-diabetics $[45,46]$. Relatively few data are available on association between T levels and IR in men, especially in patients with T1D. Two studies demonstrated a positive relationship between total $\mathrm{T}$ levels and IR in diabetic men $[47,48]$. In contrast, two studies demonstrated no correlation $[23,49]$, whereas some of them show a weak positive relationship [48]. Current data showed a positive correlation between total $\mathrm{T}$ level and IR. These controversial conclusions can be explained by the different demographic and biochemical patient characteristics; otherwise they could point to the need for additional research.

Birkeland et al. [47] reported that the level of SHBG represents an index of IR, and many studies have confirmed this result [16], but current study results did not show any relation between SHBG and IR, estimated by eGDR.

Furthermore, analyzing IR in T1D, we found increased IR frequency according to eGDR in obese patients with T1D. It is commonly known that obesity is related to IR. Low grade inflammatory cells (like adiponectins, tumor necrosis factor, etc.) in white adipose tissue directly cause IR [50]. Obesity in T1D might be explained in part by intensive insulin therapy, which causes insulin-induced IR and weight gain, increased frequency of hypoglycemic episodes, and by genetic traits. However, hypoglycemia frequency and insulin dose per kilo did not differ from the lean group in the current study. Moreover, these study results revealed that patients with T1D and a positive family history of T2D were not susceptible to weight gain, while MS phenotype prevalence was higher in obese than in lean patients with T1D, with a tendency to significant difference. Purnell et al. analyzed the relationship of family history of T2D with weight gain and dyslipidemia. They concluded the opposite, i.e., subjects with T1D with a family history of T2D had a greater weight gain and dyslipidemia rate [51]. More studies are needed to gain further insights into the anthropometric and metabolic determinants of IR in T1D.
In conclusion, this cross-sectional study of patients with T1D estimated that the cutoff value of eGDR that reflects IR is less than $6.4 \mathrm{mg} \mathrm{kg}^{-1} \mathrm{~min}^{-1}$. According to this value, patients with IR more frequently had microvascular complications and CVD events. eGDR less than $2.3 \mathrm{mg} \mathrm{kg}^{-1} \mathrm{~min}^{-1}$ was a cutoff for negative CVD outcomes. Lower eGDR, longer diabetes duration, and lower HbA1c significantly increased CVD outcomes risk. Also, eGDR was significantly lower in smoking, obese, male patients aged over 50 years, and with long-standing T1D. Moreover, T levels in men had a positive correlation with IR in T1D. Patients with T1D and a positive family history of T2D were not susceptible to weight gain, while MS phenotype prevalence tended to be higher in obese than in lean patients with T1D.

\section{Limitations of the study}

The following limitations of the current study should be taken into account. First, the study design. The study was cross-sectional and thus limited the ability to draw valid conclusions of a temporal association between IR development and micro- and macrovascular diabetes complications. The second limitation was the relatively small sample size, which could decrease the probability to detect real differences between groups. The third was the lower percentage of patients who were tested for sex hormones ( $62 \%$ of those included in the study). This was due to financial and logistic organization difficulties. Therefore, the results related to sex hormones could be misinterpreted or possible associations missed. For example, this study has not demonstrated the relation between IR and SHBG level, whereas the majority of other studies observed this relationship; a possible explanation for this could be too small a sample in our cohort.

\section{ACKNOWLEDGEMENTS}

Funding. No funding or sponsorship was received for this study or publication of this 
article. The Rapid Service Fee was funded by the authors.

Authorship. All named authors meet the International Committee of Medical Journal Editors (ICMJE) criteria for authorship for this article, take responsibility for the integrity of the work as a whole, and have given their approval for this version to be published.

Disclosures. Diana Šimonienè, Aksana Platūkienè, Edita Prakapienè, Lina Radzevičienè and Džilda Veličkienè have nothing to declare.

Compliance with Ethics Guidelines. All procedures followed were in accordance with the ethical standards of the responsible committee on human experimentation (by the Kaunas Regional Biomedical Research Ethics Committee) and with the Helsinki Declaration of 1975, as revised in 2013. In accordance with Springer's policy, informed consent was obtained from all patients for being included in the study.

Data Availability. All data generated or analyzed during this study are included in this published article/as supplementary information files. We thank the participants of the study.

Open Access. This article is distributed under the terms of the Creative Commons Attribution-NonCommercial 4.0 International License (http://creativecommons.org/licenses/ by-nc/4.0/), which permits any noncommercial use, distribution, and reproduction in any medium, provided you give appropriate credit to the original author(s) and the source, provide a link to the Creative Commons license, and indicate if changes were made.

\section{REFERENCES}

1. Priya G, Kalra S. A review of insulin resistance in type 1 diabetes: is there a place for adjunctive metformin? Diabetes Ther. 2018;9(1):349-61.

2. Pankow JS, Jacobs DR Jr, Steinberger J, Moran A, Sinaiko AR. Insulin resistance and cardiovascular disease risk factors in children of parents with the insulin resistance (metabolic) syndrome. Diabetes Care. 2004;27(3):775-80.

3. Cleland SJ, Fisher BM, Colhoun HM, Sattar N, Petrie JR. Insulin resistance in type 1 diabetes: what is 'double diabetes' and what are the risks? Diabetologia. 2013;56(7):1462-70.

4. Trevisan M, Liu J, Bahsas FB, Menotti A. Syndrome $\mathrm{X}$ and mortality: a population-based study: Risk Factor and Life Expectancy Research Group. Am J Epidemiol. 1998;148:958-66.

5. Conway B, Miller RG, Costacou T, et al. Temporal patterns in overweight and obesity in type 1 diabetes. Diabet Med. 2010;27(4):398-404.

6. Kjaer IG, Kolle E, Hansen BH, Anderssen SA, Torstveit $\mathrm{MK}$. Obesity prevalence in Norwegian adults assessed by body mass index, waist circumference and fat mass percentage. Clin Obes. 2015;5(4): 211-8.

7. Ishikawa M, Pruneda ML, Adams-Huet B, Raskin P. Obesity-independent hyperinsulinemia in nondiabetic first-degree relatives of individuals with type 2 diabetes. Diabetes. 1998;47:788-92.

8. Chillarón JJ, Flores-Le-Roux JA, Benaiges D, Botet JP. Type 1 diabetes, metabolic syndrome and cardiovascular risk. Metabolism. 2014;63(2):181-7.

9. Livingstone SJ, Looker HC, Hothersall EJ, et al. Risk of cardiovascular disease and total mortality in adults with type 1 diabetes: Scottish Registry Linkage Study. PLoS Med. 2012;9(10):e1001321.

10. Epstein EJ, Osman JL, Cohen HW, Rajpathak SN, Lewis O, Crandall JP. Use of the estimated glucose disposal rate as a measure of insulin resistance in an urban multiethnic population with type 1 diabetes. Diabetes Care. 2013;36(8):2280-5.

11. Chillarón JJ, Goday A, Flores-Le-Roux JA, et al. Estimated glucose disposal rate in assessment of the metabolic syndrome and microvascular complications in patients with type 1 diabetes. J Clin Endocrinol Metab. 2009;94(9):3530-4.

12. Nyström T, Holzmann MJ, Eliasson B, Svensson AM, Sartipy U. Estimated glucose disposal rate predicts mortality in adults with type 1 diabetes. Diabetes Obes Metab. 2018;20(3):556-63.

13. Bicu ML, Bicu D, Gargavu S, Sandu M. Estimated glucose disposal rate (eGDR)-a marker for the assessment of insulin resistance in type 1 diabetes mellitus. Rom J Diabetes Nutr Metab Dis. 2016;23(2):I77-182. 
14. Daka B, Rosen T, Jansson PA, Råstam L, Larsson CA, Lindblad $\mathrm{U}$. Inverse association between serum insulin and sex hormone-binding globulin in a population survey in Sweden. Endocr Connect. 2012;2(1):18-22.

15. Bruns CM, Kemnitz JW. Sex hormones, insulin sensitivity, and diabetes mellitus. ILAR J. 2004;45(2):160-9.

16. Wallace IR, McKinley MC, Bell PM, Hunter SJ. Sex hormone binding globulin and insulin resistance. J Clin Endocrinol. 2013;78:321-9.

17. Laaksonen DE, Niskanen L, Punnonen K, et al. Testosterone and sex hormone-binding globulin predict the metabolic syndrome and diabetes in middle-aged men. Diabetes Care. 2004;27(5): $1036-41$.

18. Heald AH, Anderson SG, Ivison F, et al. Low sex hormone binding globulin is a potential marker for the metabolic syndrome in different ethnic groups. Exp Clin Endocrinol Diabetes. 2005;113:522-8.

19. Christensen L, Hagen C, Henriksen JE, Haug E. Elevated levels of sex hormones and sex hormone binding globulin in male patients with insulin dependent diabetes mellitus. Effect of improved blood glucose regulation. Dan Med Bull. 1997;44(5):547-50.

20. Haffner SM. Sex hormones, obesity, fat distribution, type 2 diabetes and insulin resistance: epidemiological and clinical correlation. Int J Obes Relat Metab Disord. 2000;24(Suppl.):56-8.

21. Oh JY, Barrett-Connor E, Wedick NM, Wingard DL. Endogenous sex hormones and the development of type 2 diabetes in older men and women: the Rancho Bernardo study. Diabetes Care. 2002;25(1): 55-60.

22. Al Hayek AA, Khader YS, Jafal S, Khawaja N, Robert AA, Ajlouni K. Prevalence of low testosterone levels in men with type 2 diabetes mellitus: a cross-sectional study. J Family Community Med. 2013;20(3): 179-86.

23. Grossmann M, Thomas MC, Panagiotopoulos S, et al. Low testosterone levels are common and associated with insulin resistance in men with diabetes. J Clin Endocrinol Metab. 2008;93(5): 1834-40.

24. van Dam EWCM, Dekker JM, Lentjes EGWM, et al. Steroids in adult men with type 1 diabetes: a tendency to hypogonadism. Diabetes Care. 2003;26(6): 1812-8.

25. Rezaianzadeh A, Namayandeh SM, Sadr SM. National Cholesterol Education Program Adult
Treatment Panel III versus International Diabetic Federation definition of metabolic syndrome, which one is associated with diabetes mellitus and coronary artery disease? Int J Prev Med. 2012;3(8): $552-8$.

26. Expert Panel on the Identification, Evaluation, and Treatment of Overweight and Obesity in Adults. Executive summary of the clinical guidelines on the identification, evaluation, and treatment of overweight and obesity in adults. Arch Intern Med. 1998;158(17):1855-67.

27. Williams K, Erbey J, Becker D, Arslanian S. Can clinical factors estimate insulin resistance in type 1 diabetes? Diabetes. 2000;49(4):626-32.

28. Bulum T, Duvnjak L, Prkacin I. Estimated glucose disposal rate in assessment of renal function in patients with type 1 diabetes. Coll Antropol. 2012;36(2):459-65.

29. Tervaert TW, Mooyaart AL, Amann K, et al. Pathologic classification of diabetic nephropathy. J Am Soc Nephrol. 2010;21(4):556-63.

30. Tam CS, Xie W, Johnson WD, Cefalu WT, Redman LM, Ravussin E. Defining insulin resistance from hyperinsulinemic-euglycemic clamps. Diabetes Care. 2012;35(7):1605-10.

31. Vladu M, Clenciu D, Efrem IC, et al. Insulin resistance and chronic kidney disease in patients with type 1 diabetes mellitus. J Nutr Metab. 2017;2(6): 253-9.

32. Pop A, Clenciu D, Anghel M, et al. Insulin resistance is associated with all chronic complications in type 1 diabetes. J Diabetes. 2016;8(2):220-8.

33. Olson JC, Erbey JR, Williams KV, et al. Subclinical atherosclerosis and estimated glucose disposal rate as predictors of mortality in type 1 diabetes. Ann Epidemiol. 2002;12:331-7.

34. Chaturvedi N, Sjoelie AK, Porta M, et al. Markers of insulin resistance are strong risk factors for retinopathy incidence in type 1 diabetes. The EURODIAB Prospective Complication. Diabetes Care. 2001;24(2):284-9.

35. Kilpatrick ES, Rigby AS, Atkin SL. Insulin resistance, the metabolic syndrome, and complication risk in type 1 diabetes: "Double diabetes" in the Diabetes Control and Complications Trial. Diabetes Care. 2007;30(3):707-12.

36. The Diabetes Control and Complications Trial Research Group. The effect of intensive diabetes therapy on measures of autonomic nervous system function in the Diabetes Control and Complications Trial (DCCT). Diabetologia. 1998;41:416-23. 
37. Purnell JQ, Hokanson JE, Marcovina SM, Steffes MW, Cleary PA, Brunzell JD. Effect of excessive weight gain with intensive therapy of type 1 diabetes on lipid levels and blood pressure: results from the DCCT. Diabetes Control and Complications Trial. JAMA. 1998;280(2):140-6.

38. Nathan DM, Buse JB, Davidson MB, et al. Medical management of hyperglycemia in type 2 diabetes: a consensus algorithm for the initiation and adjustment of therapy: a consensus statement of the American Diabetes Association and the European Association for the Study of Diabetes. Diabetes Care. 2009;32(1):193-203.

39. Hanefeld M, Frier BM, Pistrosch F. Hypoglycemia and cardiovascular risk: is there a major link? Diabetes Care. 2016;39(Sup 2):S205-9.

40. Teixeira MM, Diniz Mde F, Reis JS, et al. Insulin resistance and associated factors in patients with type 1 diabetes. Diabetol Metab Syndr. 2014;6:131.

41. Danielson KK, Drum ML, Estrada CL, Lipton RB. Racial and ethnic differences in an estimated measure of insulin resistance among individuals with type 1 diabetes. Diabetes Care. 2009;33(3):614-9.

42. Geer EB, Shen W. Gender differences in insulin resistance, body composition, and energy balance. Gend Med. 2009;6(Sup 1):60-75.

43. Uruska A, Araszkiewicz A, Uruski P, Naskret D, Zozulinska-Ziolkiewicz D. Smokers with type 1 diabetes are more insulin-resistant. Results from Poznan Prospective Study (PoProStu). Clin Diabetol. 2018;7(2):122-7.

44. Bergman BC, Perreault L, Hunerdosse D, et al. Novel and reversible mechanisms of smoking-induced insulin resistance in humans. Diabetes. 2012;61(12):3156-66.

45. Andersson B, Marin P, Lissner L, Vermeulen A, Bjorntorp P. Testosterone concentrations in women and men with NIDDM. Diabetes Care. 1994;17: 405-11.

46. Dhindsa S, Prabhakar S, Sethi M, Bandyopadhyay A, Chaudhuri A, Dandona P. Frequent occurrence of hypogonadotropic hypogonadism in type 2 diabetes. J Clin Endocrinol Metab. 2004;89:5462-8.

47. Birkeland KI, Hanssen KF, Torjesen PA, Vaaler S. Level of sex hormone-binding globulin is positively correlated with insulin sensitivity in men with type 2 diabetes. J Clin Endocrinol Metab. 1993;76:275-8.

48. Haffner SM, Karhapaa P, Mykkanen L, Laakso M. Insulin resistance, body fat distribution, and sex hormones in men. Diabetes. 1994;43:212-9.

49. Abate N, Haffner SM, Garg A, Peshock RM, Grundy SM. Sex steroid hormones, upper body obesity, and insulin resistance. Clin Endocrinol Metab. 2002;87: 4522-7.

50. Weyer C, Funahashi T, Tanaka S, et al. Hypoadiponectinemia in obesity and type 2 diabetes: close association with insulin resistance and hyperinsulinemia. J Clin Endocrinol Metab. 2001;86(5): 1930-5.

51. Purnell JQ, Dev RK, Steffes MW, et al. Relationship of family history of type 2 diabetes, hypoglycemia, and autoantibodies to weight gain and lipids with intensive and conventional therapy in the Diabetes Control and Complications Trial. Diabetes. 2003;52(10):2623-9. 